\title{
Reorienting the Role of Middle Managers for Creating Value within the Organization: an Economical, Social and Ethical Proposal
}

\author{
Reorientar el papel de los mandos intermedios \\ para crear valor dentro de la organización: una \\ propuesta económica, social y ética
}

\section{LUCIO LESCANO DUNCAN}

General Director, CAME School of Middle

Management-Perú.

llescano@came.edu.pe

Abstract: Many studies have focused on customer value and how it is created based on the performance of front-line employees in addition to the unquestionable role of top management. It is also necessary to analyze the creation of value within the organization from the role of middle managers. These managers are crucial to orient employees for promoting value for customers that in turn creates value for stakeholders.

Using an anthropological model we analyzed the creation of value in three organizational dimensions: economical, social and ethical, and how the role of middle managers contributes to this purpose. We applied a survey to 263 middle managers to identify their views about their role and their needs for assuming it. We designed and executed a program for developing the competencies and personal qualities required for fulfilling their role focused on the creation of value. This study included semi-structured interviews to explore the experience and beliefs of these managers about the main tasks they face according to the three dimensions of the model. Through the results obtained we designed a scheme to arrange the role of these managers. Finally, we validated a model to prepare them as leaders for creating value.

Keywords: Role of Middle Managers, Customer Value, Value Creation, Value for Stakeholders
Resumen: Muchos estudios se han centrado en el valor para el cliente y en cómo se crea en función del rendimiento de los empleados de primera línea, además del papel incuestionable de la alta dirección. También es necesario analizar la creación de valor dentro de la organización desde el rol de los mandos intermedios. Estos mandos son cruciales para orientar a los empleados a promover el valor para los clientes que, a su vez crea valor para las partes interesadas.

Utilizando un modelo antropológico, analizamos la creación de valor en tres dimensiones organizativas: económica, social y ética, y cómo el papel de los gerentes medios contribuye a este propósito. Aplicamos una encuesta a 263 mandos intermedios para identificar sus puntos de vista acerca de su función y sus necesidades para asumirla. Diseñamos y ejecutamos un programa para desarrollar las competencias y cualidades personales necesarias para cumplir con su rol centrado en la creación de valor. Este estudio incluyó entrevistas semiestructuradas para explorar la experiencia y las creencias de estos gerentes en torno a las tareas principales que afrontan, de acuerdo con las tres dimensiones del modelo. A través de los resultados obtenidos, diseñamos un esquema para organizar el rol de estos gerentes. Finalmente, validamos un modelo para prepararlos como líderes para crear valor.

Palabras clave: Rol de los mandos intermedios, Valor para el cliente, Creación de Valor, Valor para los stakeholders 


\section{INTRODUCTION}

To really understand the value for customers it is necessary to analyze the creation of value within the organization from the different dimensions. There is not enough research about the role of middle managers in creating value, and how should be prepared to do that. For this purpose first we analyzed relevant studies that can give us a clear vision of their work within the organization.

The main thing to keep in mind is that organizations have to create several types of value. It starts with the effective management of the business, for which the objective is to create economical value that allows satisfying the material needs of those who participate in the operational process and those who are related to it. Secondly, organizations need to develop the ability to implement their operational processes and innovate it continuously. Then, the goal is to create social value that contributes to meet the particular needs and expectations of both customers and employees. Third, it is required the influence of a consistent leadership at all levels, and specifically at the middle, as it exerts an impact to the following levels to generate identification with the organization. Here the objective will be to create ethical value that inspires commitment to an external mission, in front of the customers, and an internal mission, in front of the collaborators. The creation of value in the economical, social and ethical dimensions will produce benefits for customers. Therefore, in our study we analyze the role of middle managers to fulfill the crucial mission of creating value according to those organizational dimensions: a) the creation of economical value, b) the creation of organizational capability-social value, and c) the creation of commitment to the mission-ethical value.

To examine the creation of value we used an anthropological model that let us understand how those three dimensions are connected ${ }^{1}$. We applied this anthropological view to the tasks of middle managers and designed a scheme to explain how these should be integrated according to their role in the organization. We identified the needs of these managers to assume the role for creating value through a survey applied to 263 middle managers. According to the data obtained we defined a program to develop their main competencies and personal qualities in order to consolidate their leadership for that purpose. Most of the studies about these managers analyze the diversity of their

1 Pérez López, J. A. (2000). 
roles, influences, contributions and limitations, but not necessarily propose a concrete way to prepare them according to what they face in the organization. So, we prepared these 263 managers through our Middle Managers' Development Program ${ }^{2}$ and achieved important results. We also applied semistructured interviews in order to understand the motivations they believe are essentials for creating the three types of value and how this task should be carried out. With our findings we support the reorientation of the role of these managers and show their contribution to effectively guide employees' talent for creating and delivering value for customers. If an organization creates consistently customer value, promotes customer satisfaction and customer loyalty ${ }^{3}$ that in turn favors the consolidation and continuity of the organization, then it is viable to create value for stakeholders. Through the results of a second survey we validated a model with the main competencies and personal qualities that middle managers should develop to participate fruitfully at the three organizational dimensions.

\section{The situation of Middle Managers}

Commonly a middle manager is responsible for putting the plans into action and achieving the organizational objectives. To do that, receives and transmits orders, collaborate with colleagues and receive collaboration. Thus, he acts as subordinate, relates to his peers and is superior to others ${ }^{4}$. It is a demanding job that requires diverse skills and resources. The middle managers maintain a hectic pace of work because they are responsible for turning plans and strategies into action, and usually receive little support and recognition from top management and workers ${ }^{5}$. Middle managers are the machinery of an organization in which responsibility is to translate the corporate strategy in actions and results ${ }^{6}$. While top managers plan and define the direction of the organization, middle managers conduct operations according to that direction. Thus, these managers carry out the agenda of top management ${ }^{7}$. The middle manager is the link between the purpose of the strategy formulated by top management and the action of the company to provide the product and/or

2 A program for developing competencies and personal qualities for middle managers in order to consolidate their leadership through a balanced vision among the economical, social and ethical aspects.

3 Heskett, J.; Schlesinger, L. and Sasser, W. (2003).

4 Uyterhoeven, H. (1989).

5 Schlesinger, L. and Oshry, B. (1982).

6 Haneberg, L. (2005), p. 32.

7 Osterman, P. (2008). 
service, to be executed by employees under the direction of the middle management ${ }^{8}$. These managers assume the execution of the plan and guide their subordinates to implement processes, which cannot be done by top management. They convert the mission and strategy into concrete actions to achieve goals that benefit all those involved with the organization.

For a long time, the problems faced by middle managers have been observed. The main problem is the lack of authority of these managers to make decisions and their dependence on others to obtain results 9 . The middle management carries a great responsibility, despite having a limited authority. These managers have a double role as coach and player, so they must delegate and $\mathrm{act}^{10}$. The diverse tasks and responsibilities that they assume and the relationships that maintain obligate these managers to speak different languages in the organization: with top managers, colleagues, subordinates, in addition to interacting with customers and/or suppliers. Therefore, for these managers to prosper it has been argued that they have to become specialists and at the same time generalists and team members ${ }^{11}$. Then, it is not enough for them to develop a specialization, they must become generalists and acquire new skills to manage changes, forge relationships within and outside the organization, and use initiative to achieve more difficult goals every time ${ }^{12}$.

\section{The role of middle managers}

The roles of middle managers have been defined as: promoting new strategic alternatives, knowing how to synthesize and communicate them, facilitating adaptation and organizational learning, and executing the strategy managing changes ${ }^{13}$. Other researchers argue that managers must fulfill the roles of creators to implement the strategy, influential to solve problems, stabilizers to avoid chaos and promote internal improvement, and drivers for a continuous transformation ${ }^{14}$. Disruptions and faster changes in the way to do businesses push organizations to increase their adaptation capacity in order to survive and take advantage of new market demands. Given this reality, mid-

8 Lescano Duncan, L. (2011).

9 Kay, E. (1974).

10 Uyterhoeven, H. (1989).

11 Mc Dermott, L. (1995).

12 Clarke, M. (1998).

13 Floyd, D. and Wooldridge, B. (1997).

14 Dauphinaus, W. (1996). 
dle managers must be key allies for the implementation of radical changes. Thus, they are entrepreneurs because they add value through new ideas, communicators because they conduct the changes and involve the staff of the entire organization, therapists because they motivate employees and balancers since they handle tension between the continuity and the change ${ }^{15}$. The emotional aspect that middle managers have to face when implementing organizational changes has been emphasized as an important aspect of their role ${ }^{16}$.

Some researchers argue that these managers are translators and executors of policies and plans, and motivators of staff, but emphasize that motivation is the primary task in successful companies ${ }^{17}$. Others point out that organizations cannot dispense with the middle management because their role as entrepreneurs and agents of change are vital to face new challenges ${ }^{18}$. The middle managers must have an entrepreneurial mentality and be in constant search to provide quality and service at a competitive $\operatorname{cost}^{19}$. As they are in the full execution of the processes have the possibility to conceive, suggest and implement ideas that top managers had not even thought about ${ }^{20}$. The middle managers are necessary to facilitate the performance of the company in creativity, innovation and intensive knowledge of the industry ${ }^{21}$. Some have highlighted that these managers practice a bureaucratic role, following an established model of operation, without considering the changing context, concentrating more on hierarchy and control, which hinders communication, coordination and integration. Thus, it has been proposed that their role be focused on defining the service mission of their team, and on teaching the members to fulfill it using resources rightly ${ }^{22}$. Therefore, the role of middle manager as a coach has been proposed in order to prepare the team to deploy its maximum potential, assuming the task of tutor, mentor, assessor and inspirer $^{23}$. Others have supported the catalyst role that drives performance by accelerating the reaction between the employee's talent and the company's goals, as well as between the employee's talent and the customer's needs ${ }^{24}$.

15 Huy, Q. N. (2001).

16 Huy, Q. N. (2001), Huy, Q. N. (2011).

17 Horovitz, J. (1994).

18 Jackson, D. and Humble, J. (1994).

19 Mc Dermott, L. (1995).

20 Kanter, R.B. (2004), p. 153.

21 Mollick, E. (2012).

22 Albrecht, K. (1992).

23 Horovitz, J. (2006), p. 191.

24 Buckingham, M. \& Coffman, C. (1999). 
The different tasks that the middle managers must fulfill have been defined by various researchers through the development of a new leadership: becoming a center leader ${ }^{25}$, acquiring a new vision of leadership ${ }^{26}$, developing a leadership focused on internal service ${ }^{27}$. The essence of the work of the middle level leader is to promote a positive learning of his staff and build a new distinctive competency of the organization to serve the customer ${ }^{28}$. For us, the responsibility of middle management demands an authority that is not based on formal systems or hierarchical levels, but on new and reoriented leadership.

They are frequently focused on new technologies and processes to get efficiency for obtaining economical results. Thus, it is observed that the changes that have sought greater efficiency and agility in the organization have affected the middle managers who feel frustrated and oppressed because they work harder every time but their compensation does not increase ${ }^{29}$. Some studies revealed that these managers feel exhausted and despised, with little recognition and lack of support from top management ${ }^{30}$. The restructuring and flattening of organizations has caused these managers to behave like entrepreneurs, take risks and evaluate performance in economic terms, efficiency and effectiveness ${ }^{31}$. Some organizations have adequately handled the changes and maintain satisfied middle managers that contribute notoriously to the success of the company, while others have ineffective managers that are often extinguishing fires, overwhelmed and uncommitted ${ }^{32}$. These managers are usually not committed to their employers and this represents an obstacle to effective organizational functioning ${ }^{33}$. In general, these managers are disappointed because they feel greater pressure due to organizational changes and the use of new technologies in order to become the organization agile, adaptable, ambidextrous, customer centered.

The role of these managers has mainly been analyzed by researchers from their contribution to the strategic dimension and from their role to create an efficient social environment in the organization ${ }^{34}$. There is important

25 Mc Dermott, L. (1995), p. 39.

26 Floyd, S. W. and Wooldridge, B. (1997).

27 Albrecht, K. (1992).

28 Lescano Duncan, L. (2012).

29 Laff, M. (2007), p. 20.

30 Pomeroy, A. (2006), p. 16.

31 Dopson, S. and Stewart, R. (2001).

32 Haneberg, L. (2005).

33 Osterman, P. (2008).

34 Floyd, S. W. and Wooldridge, B. (2017). 
study about what and how middle managers do, but there is not sufficient research about why and what for these managers do. Thus, it is required to analyze this role through a systemic vision that let us arrange the diversity they face and find out how to orient a consistent leadership at the middle level. To us it is possible through a deeper anthropological analysis.

Middle managers usually cannot provide their best contribution, because they neglect aspects that significantly affect the performance of the organization, especially human aspects like personal qualities and relationships with top managers, colleagues, subordinates and even with themselves. They frequently do not know how to promote positive learning and forge the right changes in their behavior and behaviors of subordinates for strengthening the climate and culture that are crucial aspects in each organizational unit. They are not prepared to exert an authentic leadership to create value for employees and customers ${ }^{35}$. Then, their role should be oriented to effectively integrate the strategic aspect, operational learning, and ethical growth.

\section{The reorientation of middle managers}

It is necessary to reorient the role that these managers must assume considering the consequences of the new organizational demands, i.e. information technology, automation, artificial intelligence. However, this is not easy because top management should consider them as allies recognizing their crucial role in organizational functioning, which is not usually common.

So, how can we reorient middle managers to provide their best contribution to the performance of the organization for creating value? To address this, it is necessary to amplify our understanding of the human organization. The basic purpose of the human organization is the creation and distribution of material wealth, that is, the creation of economical value. However, it is also necessary to promote satisfaction of those who are related to the company, and even the personal development of employees must also be achieved ${ }^{36}$. The results of the organization must be oriented to provide economical value but also other values that truly favor the satisfaction of the employees and their development.

35 Lescano Duncan, L. (2017).

36 Pérez López, J.A. (2000). 
The creation of value is based on the reason for being of every organization: the mission of satisfying its customers and thereby satisfying all its stakeholders. A company's job is to create superior customer value in the mind of the customer ${ }^{37}$. We understand customer value as the benefits received for burden endured. Those benefits are significantly supported through the services that are added to increase customer satisfaction and the burden is not just the price but all efforts that can produce other costs and un-satisfaction. The service plays a primary role in the value equation to increase benefits and reduce burdens ${ }^{38}$. The role of a company is to create value for its employees and customers, suppliers and partners, and therefore, for its stakeholders. The creation of value implies executing proactive, conscious, inspired and imaginative actions that create better value for customers and all stakeholders ${ }^{39}$. Although top management must define the route for the creation of value, we consider that the middle management must assume a decisive part: stimulate the practice of continuous innovation, learning and commitment of employees that make possible customer satisfaction and the scope of the organizational objectives. The service orientation of middle managers decisively influences the performance of employees, which affects the satisfaction of customers $^{40}$. However, this orientation must be broadened beyond the management of service quality in order to include new behaviors and personal qualities to create value.

Although the quality of service is integral to deliver value to customers ${ }^{41}$, recently, a partial shift in marketing, as well as other disciplines, towards a service-dominant logic of market exchange is leading to a more encompassing view on value ${ }^{42}$. Value has remained a result of the process in service exchange, with no major push on conscious value creation ${ }^{43}$. Thus, it is necessary to complement the service logic with an amplified concept of value that broadens the vision to find new and better ways to satisfy customers and all the people involved with the organization. This demands renewing the unquestionable role of the CEO, but requires reviewing the contribution of the middle management in a specific way to create value, given its key position and crucial participation.

37 Kotler, P. (2017).

38 Berry, L. (1995).

39 Mahajan, G. (2016).

40 Lescano Duncan, L. (2012).

41 Berry, L. (1995).

42 Vargo, S.; Akaka, M. and Vaughan, C. (2017).

43 Mahajan, G. (2017). 
In several researches, weak orientation and poor preparation of middle managers to face new challenges has been demonstrated, hence the need to provide them with a better development. The middle managers require correct attitudes as their best instrument to innovate ${ }^{44}$, they need competencies of three types: strategic, team participation and personal development $t^{45}$, they require four types of skills: intellectual, interpersonal, administrative and political ${ }^{46}$, they must forge specific qualities: thoroughness, persistence, discretion, persuasion and orientation to change ${ }^{47}$, they demand new skills, behaviors and competencies to manage quality focus, teamwork and downsizing ${ }^{48}$, they need specific competencies to increase service expertise, improve their management style and strengthen their character for exerting a solid service oriented leadership ${ }^{49}$.

According to literature analyzed, we propose a deeper understanding of the role of middle managers for creating value and consistently integrate their diverse tasks and challenges through an anthropological view. For that we focus on how they must face three dimensions: 1 ) how they obtain the economical results (economical value)? 2) how they forge organizational competency (social value)?, and 3) how they foster employees' commitment (ethical value)?

\section{METHODOLOGY}

To analyze the creation of value and identify the role of middle managers we used the anthropological model that integrates three realities of the organization: 1) the amount of wealth that it creates through its operation, 2) its capacity to do things, and 3) its ability to know what things should be done to meet the real needs of customers ${ }^{50}$. Thus, a manager can approach his work trying to achieve three different types of values: 1) a right relation between what is produced and what is consumed, 2) an enough degree of satisfaction of those who are related to the organization, and 3) a contribution to the perso-

\footnotetext{
44 Kay, E. (1974).

45 Mc Dermott, L. (1995).

46 Floyd, D. and Wooldridge, B. (1997).

47 Kanter, R. B. (2004).

48 Stoker, J. (2006).

49 Lescano Duncan, L. (2012).

50 Real need is that specific need that requires be correctly identified and attended in order to provide satisfaction and improvement for a person according to his particular situation. Real needs must effectively but also ethically be attended.
} 
nal development of employees, to the extent that this development depends on what the organization asks or provides them ${ }^{51}$. This model allows us to understand the functioning of the human organization to create value from an integrated vision of its three dimensions: economical, psycho-sociological and anthropological. The model works according to the action of top management, and therefore, it is useful, because from this action it is possible to define the role of middle managers, taking into account that they are the ones who implement the plans and the agenda of top executives.

As shown in figure 1, the first reality to be analyzed is one that concentrates on the interaction between the organization and the external environment. The aim is to achieve efficacy, sufficient economic results to provide the required incentives and resources. For this, it will be necessary to correctly understand this environment, in order to guide the organization with an effective strategy that allows obtaining a sufficient fund of incentives for producers that are called extrinsic motives ${ }^{52}$. This will require a structure and formal system that orders the tasks to be carried out and establishes concrete ways to manage the economic factors with efficacy. The main task in this economical dimension corresponds to top management, as it must formulate the results to be achieved and define the course for it. However, it is the middle managers who must follow this course and obtain results with their subordinates.

51 Pérez López, J. A. (2000).

52 Extrinsic motives are aspects from the reality that produce satisfaction through interactions. These motives are external results that satisfy material needs of a person. 


\section{ANTHROPOLOGICAL MODEL FOR ORGANIZATIONS}

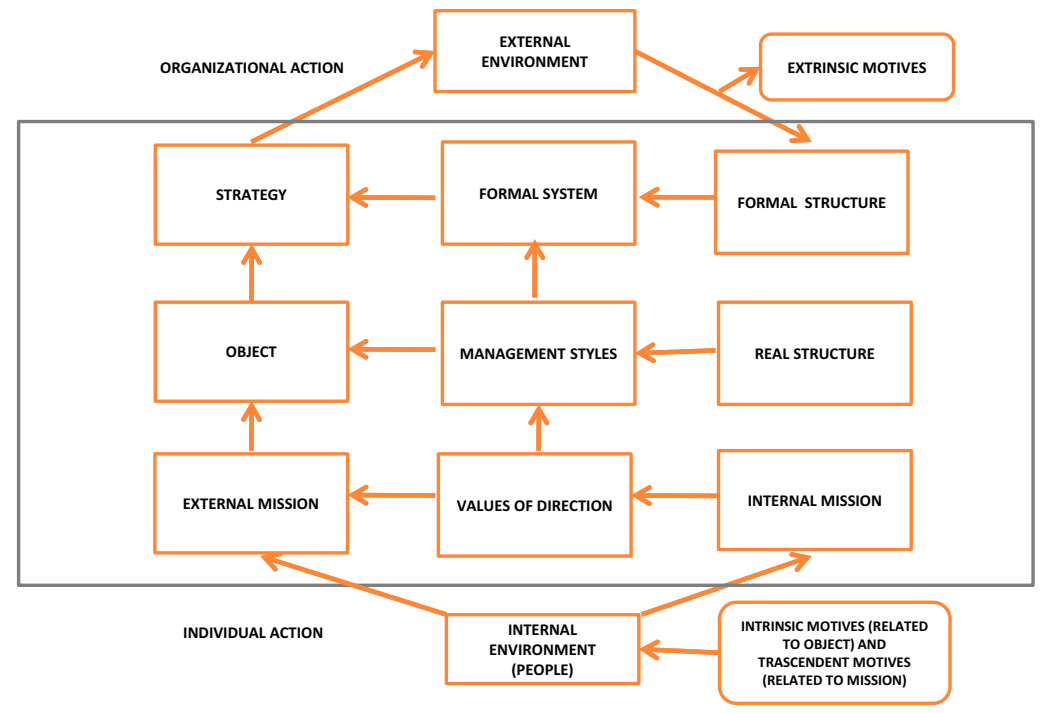

SOURCE: FOUNDATIONS OF MANAGEMENT Juan Antonio Pérez López, Ediciones Rial P, Madrid, 2000

The second reality is referred to the internal environment of the organization, and specifically to what people do, that is, to the product or service that they elaborate together. It is about the object: what the organization does in the market where it competes. People do according to the strategy, but they also do it for personal goals that each employee wants to achieve. It is clear that what the organization does is a determining factor in the motivation to work in it. Then it is necessary to consider psychological and motivational qualities that facilitate the internal coordination. In this line, the real structure includes individual characteristics that help the creation of positive spontaneous systems that facilitate the simultaneous achievement of both individual and organizational objectives. For this, management styles will be required to get people to act for internal motivation-intrinsic motives ${ }^{53}$ when

53 Intrinsic motives are aspects from the reality that determine achievements of learning of the person who makes the decision. That is to carry out actions to get learning that generates proper satisfaction. 
doing what the organization demands. This will favor an attractive environment in the organization: its ability to satisfy internal motives, that is, its value as something that satisfies people for what they are doing or can do there. With management styles that act with an efficiency criterion it will be possible to develop the capabilities that an organization requires to carry out the realization of its object, which is called its distinctive competency ${ }^{54}$. While this dimension requires policies from top management, middle managers must put them into practice to promote positive learning in their work teams and thus contribute to the creation of social value.

The third reality allows the company to be understood as an institution that is, as a human reality whose ultimate meaning is the organization of people's abilities to satisfy the needs of those same people. From this vision, the organization should integrate its three dimensions: create wealth (efficacy), through the application of specific operational capabilities (object), to meet concrete needs (external mission). The external mission represents those real needs of customers that the organization seeks to satisfy through the products or services. To fulfill this mission, it will be necessary to consider an internal mission, which represents those real needs of employees that the organization seeks to satisfy, considering that their actions determine the quality $f$ of their products and services necessary for fulfilling the purpose of the organization. The internal mission refers to the development of motivation for intrinsic and transcendent motives ${ }^{55}$ that the organization tries to achieve, through the opportune learning in its members. This organizational dimension includes the spontaneous behavior of employees to perform decisive actions towards the achievement of efficacy, as this is a consequence of satisfying the needs of other people. Spontaneous action is guided by the transcendent motives of the members and expresses the degree of identification or unity of them with the organizational efficacy.

The fulfillment of these missions, external and internal, requires that top managers consider some values when making decisions, indicated in figure 1 as values of direction. These values include: a) what the organization understands by real needs when making decisions, and b) the importance it considers to each of those real needs when making the decision. In short, the va-

54 Pérez López, J. A. (2000).

55 Transcendent motives are aspects from the reality that determine achievements of learning of people that are interacting with whom is making the decision. That is to carry out actions to generate benefits for people with whom one is interacting. 
lues of direction express how people are treated, and what type of criteria managers use when making decisions. The definite proof for the quality of values of direction is its contribution to the consolidation of unity, that is, to the identification of the members with the organizational objectives. The leadership function-when it is authentic-is to embody values that will unify the organization $^{56}$. Undoubtedly, this dimension requires a consistent leadership of top management through clear assumptions, solid values and convictions in decision-making. However, middle managers are those who accept or not, such assumptions and values when leading employees. These managers also include their own values and convictions in the decisions they make. Then, the creation of value requires not only that top, but also middle managers embrace solid moral values that orient them to assume their mission. Thus, these managers contribute to the strengthening of the ethical value in each unit.

According to the three dimensions of the anthropological model we adjusted our three questions: how can they achieve organizational objectives by executing the strategy-economical value? How should they carry out the object of the organization taking into account the spontaneous reality beyond the formal system-social value? And how do they contribute to the fulfillment of the external and internal mission through an authentic leadership-ethical value?

To answer these questions this work was structured in three stages: 1) a survey at the beginning of the process, 2) execution of the Program for developing competencies and fostering positive habits simultaneously with individual sessions of coaching, and also a schedule of qualitative interviews, and 3) a survey at the end of the process. The study was carried out to a group of 263 middle managers of large and medium companies of local and international operation, participants of our Development Program for middle managers between 2011 and 2016. These managers held the position of heads of department, project or equivalent. Most of them had a professional career, some with a master's degree and few of them with some college studies. In the first stage we applied a questionnaire whose purpose was to identify the vision of middle managers about: a) their fundamental role in the functioning of the organization, b) the main problems they face in the relationship with their subordinates, colleagues and superiors, and c) the skills they need to develop to fulfill their role. In the second stage we executed the Program to prepare middle managers for fulfilling their role and orient them for achieving eco-

56 Pérez López, J.A. (2000). 
nomic results-efficacy, creating positive learning environment-attractiveness, and promoting the commitment of employees to the mission and objectivesunity. Likewise, the schedule of interviews was carried out in order to get and analyze in a deeper way the perspectives and motivations of the participants to fulfill their role in these three dimensions. For the third stage we applied a questionnaire for verifying: a) the competencies developed and habits strengthened, b) the development of their leadership and, c) the improvement of their relationships with members of the organization to fulfill their role. To analyze the quantitative and qualitative data considering the amount of participants we used the application of adequate functions of Excel Program, and assured the quality of this work through 3 analysts with knowledge and experience in this context. We designed the questionnaires according to the practices suggested for this research tool ${ }^{57}$. We have considered the main results of these surveys that let us demonstrate the usefulness of this process. We show those responses of the two questionnaires (stage 1 and 3) that were indicated by more than $50 \%$ of participants in each group.

\section{RESULTS}

The first questionnaire was applied to each group of middle managers, total 13 groups, 263 participants, with an average of 20 participants per group. We present by appendix the main quantitative results.

In the second stage a 130 hours Program was executed for each group of middle managers. It was focused on the development of competencies and habits to promote the leadership of participants. 245 participants met the requirements to certify this program, and about $7 \%$ (18 participants) failed to certify it. Simultaneously, sessions for coaching contributed to most of participants to focus on their particular needs. The semi-structured individual interviews were scheduled for middle managers, total 263 participants. We applied the suggested practices for this methodology through open-ended questions and experienced interviewers. Two interviews were conducted with 137 participants $(52 \%)$, and an interview was conducted with 126 participants (48\%), all of them during the execution of the program. We present here the main results of interviews:

57 Malhotra, N. (2008). 
In relation to our first question: how can you achieve the objectives executing the organizational strategy?

The majority of middle managers expressed that they need to learn how to positively influence subordinates. The most of managers mentioned the influence on subordinates as the main factor to achieve objectives. Likewise, many of them stated that they should foster the commitment of their subordinates, but recognized that it is not an easy task. They also indicated that it is through their leadership in work team that they can effectively execute the strategy to achieve the objectives. One manager manifested: «I should assume a leadership to orient my subordinates as a team, giving them the meaning of their work in order to achieve the organizational objectives». Other manager expressed: «As a leader I have to promote effective meetings for listening and discussing with the members of my team about how to achieve the objectives».

On the other hand, middle managers mentioned that an important factor for achieving objectives is the relationship with the members of the organization. Most of them said that it is especially necessary to strengthen interpersonal relationships with subordinates. Others emphasized the relationships with colleagues of other units, and some remarked especially the relationship with superior. The majority believe that through positive relationships it is possible to increase their contribution as middle manager. These participants expressed that they must develop a leadership for fostering teamwork of their subordinates and strengthen their motivation. One of them said: «Now I'm interested in knowing more about each of my subordinates, their problems and needs to better orient them for achieving our goals according to every situation». Other manager stated: «It is important to align the personal objectives of each subordinate with the organizational objectives, and support him to obtain both». About the relationship with colleagues one manager expressed: «We have to better understand the work and needs of colleagues to collaborate with them especially when they are overworked». Other manager said: «With colleagues it is important to accept positive criticism and to show the attitude of tolerance, respect and harmony». Other said: «The practice of active listening and assertive communication with colleagues of other departments is crucial to achieve organizational objectives». And about relationship with the boss, one said: «The main aspect is to ask feedback from my superior in order to improve the performance of my team», other stated: «To understand clearly what your boss is trying to orient about strategy, objectives, and organizational tasks». 
Likewise, other middle managers considered that it is also necessary to monitor the appropriate operational indicators in addition to rightly understand the formal system: policies, procedures, strategy.

1. In relation to our second question: how should you increase the distinctive competency of the organization considering the spontaneous reality beyond the formal system?

The majority of participants mentioned the communication as a main factor for increasing the organizational competency. They stated that it is necessary to improve their style of communication and emphasized the informal environment as the most relevant aspect when coordinating and working with others, subordinates and colleagues. For instance, one participant manifested: «It is a key effort to focus on the informal aspects of our communication and relationship with collaborators». Some of them indicated that a complicated issue is to appropriately conduct the organizational changes. One said: «To undertake the changes we have to foster an open mind and flexibility in ourselves and subordinates and it demands new attitudes and abilities». Most of them referred to the talent and preparation of their collaborators as a key aspect to increase the distinctive competency. They said that it is imperative to help subordinates for developing their talent through a continuous learning. A manager expressed: «I have to constantly train and prepare my subordinates in order to improve their contribution to our team and the organization». Other said: «We need to be persistent about the continuous improvement of operational processes and the better use of resources». Other manifested: «To be more competitive it is necessary to train all the levels, to dialog and share feedback mutually among units». In general, middle managers interviewed demanded a better preparation to improve their contribution for increasing the competency of the organization. An important group of managers referred to the improvement of the interpersonal relationships among collaborators as a crucial task for the organizational performance. Some of these managers emphasized the need that subordinates be oriented with a greater precision and higher motivation. And others expressed that it is very important to identify their positive and negative attitudes to find the best way to take the right actions.

Most of these managers asked that top managers facilitate more training and leadership development. One of them expressed: «We have to be prepared as leaders which means to develop professional and personal aspects to face new organizational challenges». Many of them emphasized that the dialogue and cooperation in each department and with other departments are ef- 
fective practices to increase the organizational competency. Also most of them mentioned the innovation and continuous processes' improvement as relevant factors, and pointed out the empowerment for their subordinates as one of the effective ways to increase competency. These participants said that they should apply positively the practice of feedback and coaching with their subordinates to promote constant improvement in each team. A middle manager expressed: «I'm trying to be nearer my subordinates and find out new solutions for their problems and new ways to motivate them, so they can improve their contribution».

2. In relation to our third question: how can you forge identification of collaborators with the mission and objectives through an authentic leadership?

The majority of middle managers referred to the trust and integration with employees as the most effective way to promote identification. However, these managers recognized that first each middle manager must be an example for their subordinates showing ethical behavior. A participant manifested: «One must act always as an example for collaborators fostering ethical values among them and correcting those un-ethical situations at work». Other participant said: «I feel that my subordinates trust me if I'm trying to be honest and fair, so they can tell me about their problems and concerns». One manager expressed: «We have to be coherent through our acts and words and forge this attitude among employees in order to integrate them». On the other hand, many participants considered that it is mandatory that the head of the team be first committed to inspire and encourage the commitment and identification of subordinates with the mission and objectives. One manager expressed: «We have to behave and orient according to the corporate and ethical values as the route for all activities». Other said: «If I'm motivated and committed to achieve our goals it is possible to foster the motivation and commitment of my subordinates». So, these managers emphasized the need to be a consistent reference for collaborators but also demand that Top management clearly communicates institutional values to all organizational levels.

The most of participants considered that self-knowledge and self-control are essential personal aspects to consolidate their leadership, and that leadership is a key factor to forge trust among their subordinates. A participant expressed: «It is very important to be prudent when making decisions and be consistent with principles and values». One manager said: «I can build trust when I have patience to listen and show calm, empathy and tolerance, so selfcontrol is a key behavior». Other said: «It is very important to know and ma- 
nage my attitudes and impulses that can affect or damage my relationships with the members of my team». And other participant manifested: «We need to create a healthy environment fostering honest attitudes in the relationships with subordinates and colleagues».

Some participants manifested that they must be a support for fostering the expected behaviors of their subordinates and for promoting the integration within each unit. In addition they emphasized that it is important to facilitate the understanding of the mission and organizational objectives through both the formal and informal environment.

At the end of the process we applied a second questionnaire to each group of middle managers (13 groups, total 245 participants) in order to examine the results they achieved. We present by appendix the main quantitative results.

\section{DISCUSSION}

Through the first questionnaire the majority of middle managers responded that their fundamental role is to achieve the organizational objectives with the staff (88\%), and others considered the achievement of both the objectives of the organization and the objectives of their subordinates (85\%). So, most of managers pointed out the achievement of results that the organization and employees expect as the main role they have to assume. An important group of participants (82\%) responded that a relevant role is to connect the vision of top management with the needs of the operational level, which indicates that middle managers must understand and speak both languages: from top managers and subordinates. An important $79 \%$ considered their role for guiding work teams for the execution of the processes, thus they focused on the capacity to carry out the operational tasks with their subordinates.

On the other hand, a relevant $71 \%$ of managers responded that their role is to foster the motivation and commitment of their subordinates through their style of leadership. It is a remarkable issue because these participants focused mainly on the employees as the principal role they assume. $69 \%$ of managers indicated the effective communication and relationship with customers and employees as their fundamental role. They emphasized communication and relationships as a relevant aspect of their responsibility. These results reaffirm the studies we reviewed, so middle managers have to achieve the orga- 
nizational results, execute the operations with the staff, motivate and develop their subordinates.

However, researchers have also pointed out several problems middle managers face when assuming their role. The main problems can be summarized through the great responsibility they assume, the hectic pace of work they maintain and the diverse reality they face when dealing with people at the different levels in the organization. We believe that the complexity of their role is based on the relationships they face with top managers, subordinates, colleagues, and even with customers and suppliers. According to our anthropological analysis, the main problem should be focused on the type of relationships they have to build with the members of the organization, as well as with customers and others according to their specific responsibility. Other type of problems, i.e. strategic, operational, resources management, can be managed through technological application and easier actions, but those related to personal relationships and human interactions are usually more complex and difficult to handle, if managers are not prepared for that. That is the reason why we asked our participants about the main problems they face in their relationships to fulfill their role. About their relationships with subordinates: $74 \%$ responded that subordinates observed resistance to organizational changes, so managers require specific skills to handle the changes, $71 \%$ indicated that subordinates don't show initiative to solve problems, which reflects a lack of ability or a passive attitude, and even fear for doing something wrong. Thus, managers have to learn the best way to change these behaviors. Also $71 \%$ of managers responded that usually subordinates don't demonstrate commitment to the organization, that is a crucial challenge for bosses at the middle. A $(59 \%)$ of managers manifested that subordinates don't always follow their orders, which is a matter related to confidence and obedience between the boss and subordinate, and require convenient manners to address. Participants responded that their colleagues: lack of competencies and positive attitudes (74\%), show poor communication and weak coordination (72\%), show poor cooperation and support among units $(71 \%)$, constant delay to provide information to other units $(69 \%)$, and they are focused on their issues without disposition to attend requirements from other units $(66 \%)$. It demonstrates that commonly middle managers are not homogeneously prepared to work together, and the units in the organization basically use to work independently.

About the relationships with superior, most of the managers referred an excessive control of their work $(87 \%)$, high pressure to obtain economic results $(86 \%)$, high pressure to obtain operational processes improvement 
(83\%), lack of clear policy and orientation for managers (76\%), middle managers do not use to participate in strategic planning (72\%), lack of awareness about the problems middle managers face (62\%), poor support and personal development for middle managers (61\%). These responses indicate that top managers are mainly focused on the economic results and the operational aspect that middle managers have to assume. So, top managers usually do not understand the entire role of middle managers and what they really need to fulfill it. In several studies researchers argue that middle managers face complicated reality as they have to give and receive orders, collaborate and receive collaboration, act and delegate. This is a difficult job that requires great effort and obtains poor recognition and satisfaction. They have to understand what top managers expect and how to guide employees in order to get things done with the cooperation of their subordinates and colleagues, and even create a healthy atmosphere through motivated people. That is a hard work which demands not just knowledge, techniques and tools, but especially a solid character. Thus, middle managers require a new and consistent preparation in order to assume their role focused carefully on people and their continuous learning.

The role that these managers should assume has been proposed by researchers through several ideas: they must become entrepreneurs, creators, translators, etc. These ideas are mainly referred to the strategic dimension and formal system of the organization. Also researchers have included the role of communicator, team member, agent of change, driver (for transformation), and stabilizer (for avoiding chaos), balancer (for handling the tension continuity-change), influential (to solve problems), and the role of coach, mentor and inspirer, motivator or therapist (to support and motivate employees). These ideas are referred to the psychological and social dimensions in the organizational environment. An interesting proposal is that middle manager must be specialist and generalist. We believe that middle manager must be generalist not only specialist, as he must understand the complete organizational process not just the process of his unit as a specialist does. Through an amplified organizational vision managers can collaborate effectively with other units that represent one of the main obstacles for higher organizational performance we have seen through this study. A crucial part of the role of middle managers is to contribute to the development of talent of their subordinates as it will be a decisive aspect to both the achievement of strategic goals (economic value) and the satisfaction of customers, external and internal (social value). As we observe the role of middle managers is now more complex, diffuse 
and diverse, and the technological transformations in organizations represent a hard challenge for these managers. They have to deal with radical changes to implement new strategies and technologies, to get higher competency to constantly improve customer satisfaction. Thus we see the need to reorient their role through a clear understanding about the reality of the organizational context. That way our anthropological analysis follows three dimensions: 1) the aspects related to understand and apply new strategies for achieving organizational objectives-which implies a solid relationship with top managers to assume an economic responsibility, 2) the aspects related to implement processes with new technologies and improve them continuously to become highly competitive-which implies a solid relationship with subordinates and colleagues to assume a social responsibility, and 3) the aspects related to leadership for building trust and commitment, and contribute to the consistent functioning of the three dimensions-which implies a solid relationship with oneself to assume an ethical behavior.

The role of middle managers has not been analyzed from an integrated vision and then there is a mix of roles and tasks that needs to be reordered and better understood. We found that the majority of middle managers, more than $80 \%$, considered their role in the contribution to the creation of economical and social value. An important $79 \%$ focused their role on teamwork and the execution of processes that is related to the object of the organization and its distinctive competency, the social dimension. A relevant $71 \%$ expressed their role about the motivation and commitment of subordinates through their leadership capacity that is related to the ethical dimension, but it does not mean focus solely on this dimension. Then, it is important to remark the connection among these three dimensions: the influence on economic dimension from the social dimension, and the impact on social aspect from the ethical dimension. In other words, to create economical value it is required a particular functioning and competency that is promoted in the social aspect, and to create social value it is required the consistent ethical behavior that is forged by authentic leaders. So, the organization works through a convenient balance of these three dimensions according to each particular situation. In the literature we see that the role of middle managers has mainly been studied from the economical and psychological-social dimensions in order to boost the organizational performance and to achieve the results the organization needs. Although managers must handle these realities, their work has not sufficiently been analyzed for promoting a positive learning especially through a leadership that learns how to integrate the three dimensions maintaining the ethical 
value as the base for aligning and sustaining the other two. If the organization lacks of this type of leadership at the middle there is a high risk for destructing the value that economic and social dimensions are creating. Also, there is little analysis about the role of managers for forging the development and identification of their subordinates with the mission and objectives. The majority of studies focus on what middle managers should do and achieve, but few focus on what they need to develop and how to address this for facing the new organizational reality. Some researchers have proposed a new leadership of middle managers, i.e. center leader, new vision of middle leader, etc., but they have also been analyzed through a psychological and social view, and it does not explain how that leadership can be developed and reinforced. It is a descriptive aspect of leadership more than an evaluative study about this. As we verified in this study, middle managers use to be oriented to fulfill their role through the formal system and some practices for promoting a social environment of well-being and job satisfaction. But they do not usually develop a broad vision that links the three dimensions in which they must exert a consistent leadership. The challenge of developing an authentic leadership to generate commitment does not frequently receive the enough orientation. Hence, we consider very important to profoundly understand the informal or spontaneous reality where managers work, and the need that they assume the values of direction and ethical value as essential pillar for their role. This spontaneous reality is strongly related to the organizational climate and culture, and middle leaders in each unit are the builders or destroyers of them. These leaders are the drivers to generate an effective performance for achieving organizational and individual objectives through the commitment of the collaborators. Then, they should assume this role as builders of deep meaning and challenging work for their subordinates. It demands personal qualities and right orientation specifically to build a coherent climate and to share the values of direction for contributing to consolidate an organizational culture ${ }^{58}$. Thus, top managers should be aware about the needs that middle managers manifest. Top management uses to be more concerned on the results and resources that middle managers handle, but ignore about their capacity to influence and commit the people. These managers should learn how to in-

58 Climate and culture are the faces of the same coin, and climate can be understood as the manifestation of the organizational culture. Schein, E. H. (2010). We verified that the leadership of middle managers focused on service impacts in both climate and culture, so top managers should reinforce the relationship with them as they are contributing or not for maintaining a solid and consistent organizational culture assuming the values of direction from top management. Lescano Duncan, L. (2017). 
fluence subordinates for deploying their talent and use it to find new solutions and undertake new challenges, considering that new technologies are replacing the work of more employees every time. Middle managers must know how to create spontaneous and attractive environments where each one can develop his talent and embrace a significant cause for performing and doing his best. That is to learn how to foster the transcendent motives in subordinates, not just extrinsic or intrinsic motives. It favors a solid commitment to the mission and objectives as we have verified through this research. The problems that our participants manifested corroborate that they are basically guiding subordinates through the formal system concentrated in their issues without a whole vision about the impact of the work with colleagues of other units.

When we analyzed how middle managers can fulfill their role, through the qualitative interviews conducted, and related to the first dimension, the majority of participants expressed the need for fostering a positive influence on their subordinates through their leadership style in order to promote their commitment to the organizational objectives. Also managers manifested that relationships with the members of different levels are crucial for assuming their role related to the achievement of objectives and the execution of the strategy. We emphasize that in order to achieve the objectives through the implementation of the strategy it is necessary to create an attractive environment in each unit. Middle managers in the economic aspect have to lead productive employees to obtain higher performances according to what external environment demands. Then, their role in this dimension focuses on understanding the external environment to accurately apply the strategy, adapting it quickly to the radical changes in the new markets. About the distinctive competency, participants emphasized the communication and informal atmosphere as key issues for promoting a continuous operational learning to create and improve products and services. Their role in the social dimension should align a climate of wellbeing with a focused climate, in this case a climate focused on value for customers and employees ${ }^{59}$. This role facilitates the work of

59 Middle managers should distinguish between climate of well-being or generic climate and focused climate, and how to coherently align them. The first promotes a positive environment but is not effective to achieve specific strategic outcomes while the other contributes to implement concrete processes to obtain specific objectives. Ehrhart, G. M.; Schneider, B. and Macey, H. W. (2013). We verified that middle managers can create a focused climate that contributes to enhance employee value that promotes value for customers Lescano Duncan, L. (2018). 
employees through a healthy atmosphere and clear and attractive orientation for achieving specific organizational results and their own personal goals. The majority of managers expressed their need to improve their style of communication. That way they can strengthen the internal environment and their work with subordinates and colleagues. The style for communicating and working with others should foster positive experiences in order to get satisfied employees that it is based on intrinsic motives of people. This style includes the way to active listening, assertiveness, empathy and the management of conflicts.

In the other hand most of participants referred to the talent and preparation of the employees as key issues for increasing the competency of the organization. They recognize their own responsibility about that but also demand a better disposition from top managers for preparing and training all levels of the organization. They considered the innovation and processes' improvement as relevant parts of their role and remarked that it is viable through continuous dialogue and cooperation among colleagues of the different units. We emphasize the need of cohesion and integration among colleagues to face the object of the organization and foster its distinctive competency. Participants expressed the need to empower their subordinates and provide feedback and coaching as effective practices to boost their performance. About the way to forge identification of employees with the mission and objectives most of participants emphasized the trust and integration as the main aspects to achieve that. At the same time they manifested that it is necessary to be firstly committed to that mission and objectives in order to strongly influence in collaborators. Participants in general recognized that they must be an example about the expected behaviors of their subordinates. They indicated that selfknowledge and self-control are essential efforts to be a coherent reference for subordinates based on ethical aspects and values. As a result of this process we observed that they have a positive disposition to forge identification and commitment of their subordinates. Figure 2 represents the application of the anthropological model to the role of middle managers, their orientation and contribution to create value for employees (sustained through the three types of motives: extrinsic, intrinsic and transcendent) that in turn promotes the creation of value for customers, which leads to their satisfaction and loyalty that in turn favor the creation of value for stakeholders. 
Figure 2

THE ROLE OF MIDDLE MANAGERS FOR CREATING VALUE WITHIN THE ORGANIZATION: AN ANTHROPOLOGICAL VIEW

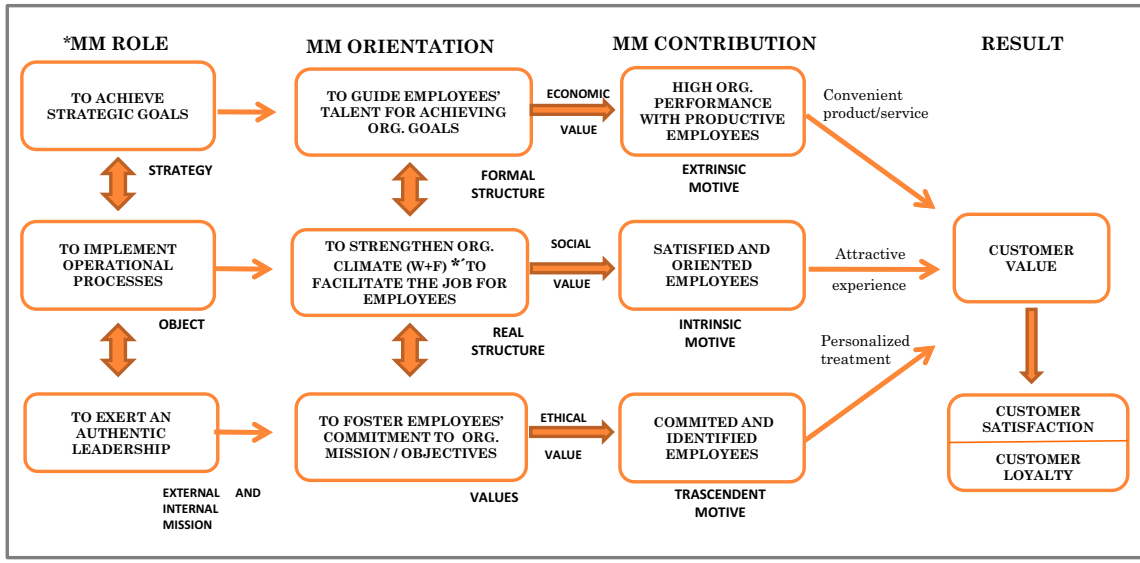

*MM: MIDDLE MANAGERS

*'w: CLIMATE OF WELLBEING

F: FOCUSED CLIMATE

SCHEME DESIGNED BY LUCIO LESCANO DUNCAN, Ph.D.2018, ACCORDING TO THE

ANTHROPOLOGICAL MODEL OF J.A. PÉREZ LÓPEZ, INDICATING THE ROLE, ORIENTATION

AND CONTRIBUTION OF MIDDLE MANAGERS FOR CREATING CUSTOMER VALUE THROUG

As we have seen in several studies middle managers have not received the adequate support for their personal development. So, in the first questionnaire, we asked our participants about their skills and needs to carry out their role: to develop my leadership (96\%), to improve my style of communication $(89 \%)$, to improve my ability of self-knowledge $(87 \%)$, to prepare my subordinates for executing the operational processes ( $82 \%)$, to foster teamwork within my unit and with other units $(75 \%)$, to improve my emotional control $(74 \%)$, to handle social and informal aspects (63\%), to promote empowerment for subordinates $(62 \%)$, to understand the organizational strategy (62\%), to promote innovation (61\%), and to develop skills for coaching (57\%). Through these responses participants are expressing their need to effectively assume their role related to get subordinates and colleagues involved for working together to achieve organizational objectives. They are recognizing the need to find the right ways to create a positive and competitive internal environment through a coherent behavior of each manager as the head of the unit. The new 
complex reality that these managers have to handle requires a special attention and better orientation and preparation. The solution should not be focused solely on more training for achieving objectives or implement new technologies and processes. The issue is to help them to acquire the vision, competencies and personal qualities to contribute for creating value in the three organizational dimensions with the ethical value as the base to strengthen and align them. The skills demanded by these managers demonstrate their need to build and maintain interpersonal relationships through a greater capacity. To reorient their role for integrating the three types of value, they should assume the values of the anthropological paradigm: to produce more than consume, to generate effective orientation and satisfaction of subordinates in each unit, and to forge their development and commitment, in addition to maintain solid relationships with colleagues and superiors, or others. For this purpose middle managers must be provided with an integral development that includes positive habits as an important aspect for consolidating their style and character. Frequently organizations focus on the acquisition of knowledge and the development of skills as the only tools to provide their employees, and it is not enough to face changes in the new context. If companies foster a distinctive competency they need observable and habitual behaviors of their employees, and that includes positive habits not just skills. If companies want to create economic value and generate a temporary positive social climate the promotion of certain soft skills through an intrinsic motivation may be sufficient. But if companies seek to forge solid commitment and learning to face difficult and challenging situations that imply sacrifice for doing the best, soft skills will not be sufficient resource. Therefore, not only developing skills or competencies focused on the economic and social dimensions, managers are ready to foster the identification, mutual support and commitment to the organizational mission and objectives. Thus, leaders at the middle level require competencies and habits to sustain them, so they can inspire employees through a transcendent motivation and forge a solid character as the base of their leadership. We see that several researchers proposed that middle managers must acquire correct attitudes for promoting innovations ${ }^{60}$, new skills to manage changes, achieve difficult goals and forge relationships ${ }^{61}$, special competencies for strategic aspect, team participation and personal development ${ }^{62}$,

60 Kay, E. (1970).

61 Clarke, M. (1998).

62 Mc Dermott, L. (1995). 
four types of skills: intellectual, interpersonal, administrative and political ${ }^{63}$, specific qualities: thoroughness, persistence, discretion, persuasion, orientation to change ${ }^{64}$, new skills and competencies for managing quality focus, teamwork and downsizing ${ }^{65}$. Most of these proposals have not explained how middle managers can develop their competencies and behaviors, and even less how they can improve their personal qualities. We propose a way to help middle managers for acquiring a broader and consistent personal development to consolidate their leadership for assuming their role for creating value. The preparation for implementing new organizational strategies and plans for executing new type of projects are not enough. Our research demonstrates that managers need to develop a leadership focused on transcendent motives aligned to extrinsic and intrinsic motives. Then, they get the best of their subordinates and build solid relationships with them, superiors and colleagues, and with themselves too.

At the end of the process we verified the results obtained through our Program. About the competencies: $90 \%$ responded that they have developed as agent of change, $88 \%$ as promoters of innovation, $87 \%$ teamwork, $85 \%$ as coaches, $82 \%$ their style of communication, $77 \%$ the capability to handle informal environment, $75 \%$ empowerment, and $72 \%$ their capability to handle the formal system. So, we considered that these are the main competencies for middle managers for exerting their role in the economical and social dimensions. In relation to the personal development obtained participants responded: $95 \%$ self-knowledge, $91 \%$ self-control, $86 \%$ positive habits: prudence, fairness, sobriety, temperance, and 57\% integrity: honesty, sincerity. This aspect was guided especially through sessions for coaching to complement efforts for fostering self-knowledge through the evaluation of their competencies, self-control through the improvement on emotional intelligence and temperance, and personal improvement through positive habits fostered. We also verified that they developed a consistent leadership for contributing to the mission and objectives: $47 \%$ totally agree, $52 \%$ agree, and $1 \%$ neutral. Finally, we asked if they have strengthened their relationships with the members of the organization for fulfilling their role: $98 \%$ responded that have improved relationships with colleagues, $98 \%$ with subordinates, $97 \%$ with myself and, $91 \%$ with superior. It is a relevant aspect for assuming their role consi-

63 Floyd, D. S. \& Wooldridge, B. (1997).

64 Kanter, R. S. (2004).

65 Stoker, J. (2006). 
dering the three dimensions for creating value: the economic result that is an important issue for top managers, social and anthropological aspects for maintaining a solid climate and consistent culture among subordinates and colleagues, and integral development for forging an ethical personal growth.

Figure 3 presents the validated model to develop competencies, personal qualities and habits to strengthen leadership. So, managers are able to build and reinforce positive relationships to contribute to the creation of value. Thus, we answered the three questions: middle managers achieve economical results through their formal capability (managing: strategic aspects, policies, objectives, extrinsic motives), create social value through their informal capability (adapting: styles, talents, personal goals, interpersonal behaviors, intrinsic motives), and forge commitment to integrate the three dimensions through transcendent motives (embracing: values, convictions and positive habits). We verified that these managers are better prepared to obtain the results expected by top management, promote attractive environment for collaborators, and achieve a personal development for themselves.

In Figure 3 we consider that communication (characterized by active listening, assertiveness, empathy, and conflict management) is the basis to exert the diverse competencies. The personal development considers integrity (honesty and sincerity) as a basis that sustains the other personal qualities.

As managerial implications we consider the need to specifically analyze how middle managers should align a climate focused on creating value with the culture, to coherently implement the strategy and achieve outcomes. We emphasize the need that these managers not be focused on creating economical value without the others values. For that it is necessary to analyze specific aspects for strengthening the crucial relationship between top and middle managers, as both of them must support to each other for creating value especially in the new context. Finally, to study how these managers should contribute to forge employees' development and commitment considering that new technologies bring new ways to perform within and out the organizational environments. 
Figure 3

\section{MIDDLE MANAGERS' MODEL FOR DEVELOPING LEADERSHIP FOCUSED ON CREATING VALUE}

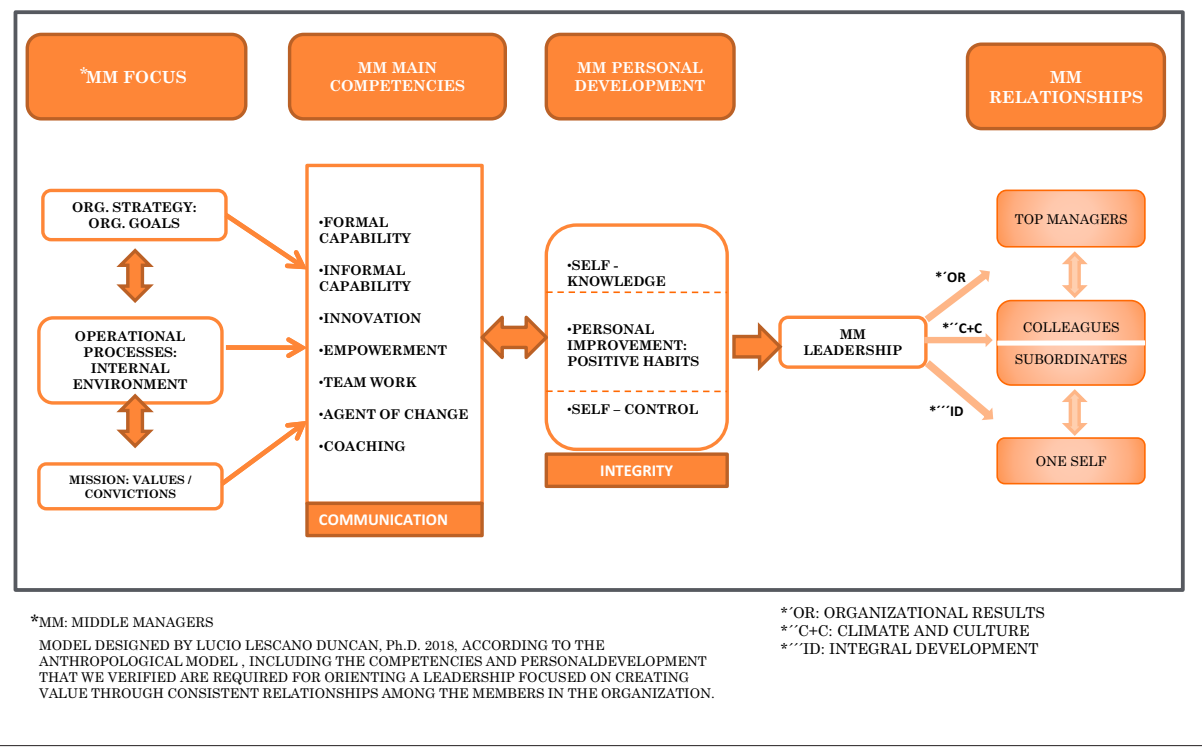

\section{CONCLUSION}

-The anthropological model utilized was useful to understand the complete vision about the creation of value in organizations and arrange the role of middle managers for that purpose. This role must be reoriented to be focused on creating value in an integrated way according to the three organizational dimensions: economical, social, ethical.

-The common orientation on economical results and social aspects in organizations is not enough. Managers should be focused effectively on the development of talent and transcendent motives of their collaborators which mean to be able to create a new type of environment for increasing the distinctive competency. This implies to learn how to orient employees for promoting an attractive manner to achieve objectives based on the main values of direction and ethical value. 
-Middle managers can contribute to create customer value through a consistent and broader orientation of employees. These managers are key factor to promote motivated employees through the three types of motives that favor their performance, satisfaction and commitment.

-The maintenance of solid relationships between middle managers and their superiors, colleagues and subordinates is crucial for enhancing the contribution of these managers for creating value. That way they can strengthen the integration based on trust and identification (unity).

-Middle managers require a particular preparation to effectively manage the creation of value, which means that top management understands the complexity of their role and support the development of their leadership. It requires a particular effort and orientation to acquire not just the required competencies but also personal qualities- positive habits- for forging the right dispositions and behaviors for fulfilling their role.

-This study has focused on middle managers who are in charge of departments or teams of large and medium companies. It limits our conclusions for other profile of managers and size of organizations.

\section{REFERENCES}

Albrecht, Karl (1992), Service for Internal Customer. How to Solve the Crisis of Leadership at Middle Level, Editorial Paidós, México.

Berry, Leonard (1995), On Great Service, a Framework for Action, The Free Press, New York.

Buckingham, Marcus and Coffman, Cur (1999), First, Break All the Rules, What the World's Greaters Managers Do Differently, Simon and Schuster Inc., New York.

Clarke, Martin (1998), “Can Specialists Be General Managers?”, Journal of Management Development, vol. 17, issue 3, pp. 191-205.

Dauphinaus, William (1996), "Who's minding The Middle Manager?", Hrfocus, pp. 12-13.

Dopson, Sue and Stewart, Rosemary (2001), "What is happening to Mid-dle Management?”, British Journal of Management, vol. 1, issue 1, pp. 3-16.

Ehrhart, G. Mark; Schneider, Benjamin and Macey, H. William. (2013), Organizational Climate and Culture, Routledge, Proquest, London. 
Floyd, Steven W. and Wooldridge, Bill (1997), The Middle Management, Prentice Hall Hispanoamericana, México.

Floyd, Steven W. and Wooldridge, Bill (2017), Handbook of Middle Management Strategy Process Research, Edward Elgar Publishing, Massachusetts.

Haneberg, Lisa (2005), "Build Middle Management Capacity", Consulting to Management, vol. 16, issue 1, pp. 32-35.

Horovitz, Jacques (2006), The Secret of Customer Service Financial Times, Pearson, Prentice Hall.

Horovitz, Jacques and Jurgens, Michelle (1994), “Total Customer Satisfaction, Metropolina de Ediciones S.A., México.

Huy, Quy Nguyen (2001), "In praise of Middle Managers", Harvard Business Review, vol. 79, Issue 8, pp. 72-79.

Huy, Quy Nguyen (2011), "How Middle Managers' Group-Focus Emotions and Social Identities Influence Strategy Implementation", Strategic Management fournal, vol. 32, pp. 1387-1410.

Jackson, David and Humble, John (1994), "Middle Managers: New Purpose, New Directions", Fournal of Management Development, vol. 13, issue 3, pp. 15-21.

Kanter, Rosabeth Moss (2004), "The Middle Managers as Innovator", Harvard Business Review, Tope-line growth, July-August issue, pp. 152-153.

Kay, Emanuel (1974), The Crisis in Middle Management, Amacom, a division of America Management Association, New York.

Kotler, Philip (2017), "Customer Value Management", Fournal of Creating Value, vol. 3, issue 2, pp. 170-172.

Laff, Michael (2007), "Middle Managers Feel Squeezed”, $T+D$, vol. 61, issue 6, p. 20.

Lescano Duncan, Lucio (2011), "Middle Managers Service Leadership", Cuadernos de Gestion, University of País Vasco, vol. 11.

Lescano Duncan, Lucio (2012), Líderes de Servicio (Service Leaders), EUINSA, Madrid.

Lescano Duncan, Lucio (2017), "How To Strengthen The Service Climate and Culture Through Service Leadership of Middle Management": Case Study of a Multinational Company", Revista Empresa y Humanismo, vol. XX, issue 1, pp. 65-96.

Lescano Duncan, Lucio (2018), "Creating a Service Climate for Enhancing Employee Value through the Role of Middle Managers: A Case Study in 
Leading Insurance Company", Journal of Creating Value, vol. 4, issue 1, pp.113.

Mahajan, Gautam (2016), Value Creation, the Definitive Guide For Business Leaders, Sage Publishing, New Delhi.

Mahajan, Gautam (2017), "Value Dominant Logic", Fournal of Creating Value, vol. 3, issue 2, pp. 217-235.

Malhotra, Naresh K. (2008), Investigación de mercados, Pearson Education, Naucalpán de Juárez.

Mc Dermott, Lynda (1995), "Reingineering Middle Management", Training and Development, vol. 49, issue 9, pp. 38-39.

Mollick, Ethan (2012), "People and Process, Suits and Innovators: Individual and Firm Performance", Strategic Management fournal, vol. 33, issue 9, pp. 1001-1015.

Osterman, Paul (2008), The Truth About Middle Managers, Harvard Business Press, Boston.

Pérez-López, Juan Antonio (2000), Foundations of Management, Ediciones Rialp, Madrid.

Pomeroy, Ann (2006), "Middle Managers Essential to Company Success", HR Magazine, vol. 51, issue 1, p. 14.

Schein, Edgar H. (2010), Organizational Culture and Leadership, John Wiley \& Sons, New Jersey.

Schlesinger, Leonard and Oshry, Barry (1982), "Quality of Work Life and the Manager: Muddle in the Middle”, Organizational Dynamics, vol. 13, issue 1, pp. 5-19.

Stoker, Janka (2006), "Leading Middle Management Consequences of Organizational Changes for Task and Behaviors of Middle Managers», Fournal of General Management, vol. 32, issue 1, pp. 32-33.

Uyterhoeven, Hugo (1989), "General Manager of Middle Level”, Harvard Business Review, vol. 67, issue 5, pp. 136-145

Vargo, Stephen; Akaka, Melissa and Vaughan, Claudia (2017), "Conceptualizing Value: A Service-Ecosystem View", Fournal of Creating Value, vol. 3, issue 2, pp. 117-124. 


\section{Appendix}

\section{First Questionnaire-Main Results}

1.- What is the fundamental role that as middle manager you assume in the functioning of your organization?

To achieve organizational objectives with the operational staff.

To achieve organizational objectives and contribute to achieve personal objectives

of my subordinates

To connect the vision of top management with the needs of the operational level.

To guide and develop work teams for executing the processes

To maintain staff motivation and commitment through my leadership style

To maintain an effective communication and relationship with customers and

employees

2.- What are the main problems you face in the relationship with your subordinates?

My subordinates observe resistance to organizational changes $74 \%$

My subordinates do not usually show initiative to solve problems .................................. $71 \%$

My subordinates do not usually demonstrate commitment to the organization............... 71\%

My subordinates do not always follow my orders and instructions ................................ 55\%

3.- What are the main problems you face in the relationship with your colleagues?

My colleagues from other units lack of competencies and positive attitudes .................. 74\%

My colleagues from other units show a poor communication and weak coordination....... $72 \%$

My colleagues from other units give poor support and cooperation .............................. $71 \%$

My colleagues from other units use to delay for providing information ............................ $69 \%$

My colleagues are usually focused on their own issues without a disposition to

attend other units

4.- What are the main problems you face in the relationship with your superior?

My superior exerts excessive control of my work .................................................... 87\%

My superior exerts high pressure to obtain economic results .......................................8. $86 \%$

My superior exerts high pressure to obtain operational processes improvement............... $83 \%$

My superior lacks of clear policy and orientation for middle managers............................ $76 \%$

My superior does not use to involve middle managers in the formulation of strategic

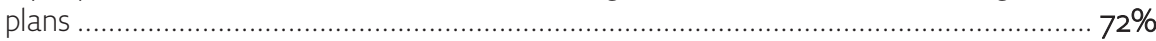

My superior is not aware about the problems middle managers face in each

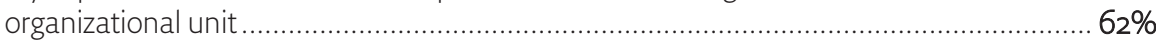

My superior gives poor support for personal development to middle managers ................ $61 \%$ 
5.- What skills do you need to develop to carry out your role as middle manager?

To develop my personal leadership $96 \%$

To improve my communication style.

To improve my ability for self-knowledge

To guide and prepare my subordinates to execute the operational processes.....

To foster team work within my unit and with other units

To improve my emotional control

To effectively handle social and informal aspects within my unit and with other units.

To promote empowerment for subordinates

To understand clearly the organizational strategy

To promote innovation for continuous processes' improvement $61 \%$

To develop skills for coaching

To develop skills for managing organizational changes $55 \%$

Source: Questionnaire designed by Lucio Lescano Duncan.

\section{Second Questionnaire-Main Results}

1.-What competencies have you developed in this process that helps you to exert your role in relation to: achieving the organizational objectives-and increase the distinctive competency?

Competencies
Agent of change
Innovation
Teamwork
Coaching
Communication
Informal Capability
Empowerment
Formal Capability

2.-What aspects of personal development have you strengthened through this process for increasing your leadership capacity to fulfill the external and internal mission?

Self-Knowledge: competencies, attitudes $95 \%$

Self-control: temperance, emotional intelligence. $91 \%$

Positive Habits: prudence, sobriety, fairness $86 \%$

Integrity: honesty, sincerity $57 \%$ 
REORIENTING THE ROLE OF MIDDLE MANAGERS FOR CREATING VALUE WITHIN THE ORGANIZATION: AN ECONOMICAL, SOCIAL AND ETHICAL PROPOSAL

3.-This development process helps me to exert a consistent leadership for contributing to the mission and organizational objectives

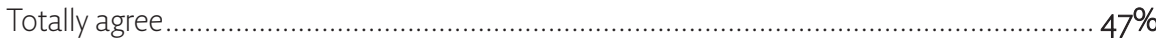

Agree

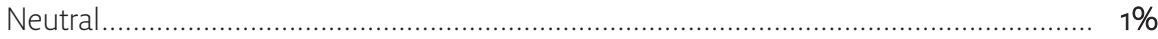

4.-With the strengthening of my leadership I have improved relationships with my superior, colleagues, subordinates, and myself in order to fulfill my role in the organization

\begin{tabular}{|c|c|}
\hline \multicolumn{2}{|l|}{ Relationships improved } \\
\hline With my colleagues... & $.98 \%$ \\
\hline With my subordinates. & $\ldots 98 \%$ \\
\hline 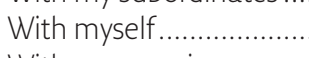 & $\cdots 97$ \\
\hline With my superior. & \\
\hline
\end{tabular}

Source: Questionnaire designed by Lucio Lescano Duncan. 
